\title{
In vitro monocyte maturation as a prediction of survival in squamous cell carcinoma of the lung
}

\author{
RICHARD G DENT AND PETER COLE \\ From the Host Defence Unit, Department of Medicine, Cardiothoracic Institute, \\ Brompton Hospital, London
}

\begin{abstract}
In vitro monocyte maturation was studied in patients with squamous cell carcinoma of the lung-limited to the ipsilateral hemithorax in 30 and more extensive in 40 . The patients were studied prospectively and initial monocyte maturation was correlated with survival. Mono- $=$ cyte maturation in patients with limited disease before treatment ranged from 3.1 to $57 \cdot 6 \%$, with $\bar{c}$ a median value of $21.4 \%$. The survival of those patients in whom monocyte maturation was less $\underset{\mathbb{\Phi}}{\stackrel{5}{*}}$ than the normal range $(<30.4 \%)$ was significantly shorter than the survival in those with normal $\vec{\oplus}$ maturation $(p<0.05)$. Four of the five patients whose initial maturation was less than $10 \% \stackrel{\infty}{-}$ proved to be inoperable at surgery. Patients with extensive disease had monocyte maturation 0 ranging from 2.4 to $52.9 \%$ with a median value of $13.2 \%$, significantly lower than in those with limited disease $(p<0.025)$. Patients with extensive disease and low monocyte maturation sur- $\frac{\partial}{0}$ vived a significantly shorter time than those with normal maturation $(p<0.005)$. The depression of monocyte development may explain the finding of negative delayed hypersensitivity skin re- $\stackrel{\mathbb{D}}{\triangle}$ actions in many patients with lung carcinoma and may prove useful as an index of prognosis.
\end{abstract}

During the past 10 years there has been increasing interest in the role of the mononuclear phagocyte system of cells (MPS) in the host response to cancer. Monocytes have been shown to have the ability to kill tumour cells in vitro, ${ }^{1}$ and the presence of macrophages within tumours has been correlated with a good prognosis. ${ }^{2}$ Treatment of animals with materials that "activate" the MPS also increases their resistance to tumour challenge. ${ }^{3}$

There have been a number of reports that monocytes from patients with cancer may function abnormally in vitro and that the degree of this abnormality may be related to prognosis. In this study we have investigated the in vitro maturation of monocytes into macrophages using cells isolated from the peripheral blood of patients with squamous cell carcinoma of the lung and related the results to patient survival.

\section{Methods}

A total of 70 patients with squamous cell carcinoma of the lung were studied during the period

\footnotetext{
Address for reprint requests: Dr Peter Cole, Host Defence Unit, Department of Medicine, Cardiothoracic Institute, Brompton Hospital, Fulham Road, London SW3 6HP.
}

July 1978 to September 1979. On the basis of clinical examination, radiology, and other appropriate investigations, 30 patients were classified as 을 having limited disease (confined to ipsilateral $\underset{x}{x}$ hemithorax with or without involved hilar nodes) $\%$ and 40 patients more extensive disease. Patients were classified by "performance status," as described by Karnofsky," from a detailed clinical history. On this scale patients with normal per- 은 formance in everyday activities score 10 and those $D$ who are moribund one. Patients who were receiving systemic corticosteroids or who had received No any specific therapy for their carcinoma were excluded from this study.

In vitro monocyte maturation was performed as $\omega$ described by Currie and Hedley. ${ }^{5}$ Briefly, $20 \mathrm{ml}$ ? of blood was defibrinated and the mononuclear 0 cells separated by density centrifugation on Ficoll- $\mathbb{\mathscr { D }}$ Triosil. The number of monocytes in the mononuclear cell preparations was assessed by staining $\frac{0}{0}$ for non-specific esterase activity. ${ }^{6}$ Fifty microlitres $\underset{\mathbb{D}}{\stackrel{D}{ }}$ of a suspension of $4 \times 10^{6}$ mononuclear cells $/ \mathrm{ml} \stackrel{\frac{\rho}{\odot}}{\circ}$ in RPMI 1640 (Flow Laboratories, Irvine, Scot- $\varrho$ land), supplemented with glutamine $2 \mathrm{mM}$, penicillin 100 units $/ \mathrm{ml}$, streptomycin $100 \mu \mathrm{g} / \mathrm{ml}$ and 8 HEPES buffer $0.02 \mathrm{M}$, and $50 \mu 1$ of autologous 
patient's serum were placed in wells of plastic microtitre plates and allowed to incubate in culture for seven days at $37^{\circ} \mathrm{C}$ in a humidified atmosphere of air containing $5 \% \mathrm{CO}_{2}$. After seven days the numbers of adherent mature macrophages remaining were counted. Monocyte maturation was then expressed as the number of mature macrophages per well at day seven as a percentage of the number of non-specific esterase positive monocytes per well on the first day. Each result represented the mean of five replicate wells.

Patients were divided into those with in vitro monocyte maturation within the normal range and those below this range. Survival curves were constructed for each group and compared statistically by the log rank test. ${ }^{7}$ Differences between groups were compared by the Mann-Whitney U test. ${ }^{8}$

\section{Results}

Sixty normal control subjects of similar age and sex distribution to the patients with cancer were investigated on a total of 120 occasions. The range of in vitro monocyte maturation in these subjects was $30 \cdot 4$ to $62 \cdot 0 \%$.

\section{PATIENTS WITH SQUAMOUS CELL CARCINOMA}

LIMITED TO THE IPSILATERAL HEMITHORAX

Monocyte maturation in this group of 30 patients ranged from $3 \cdot 1$ to $57 \cdot 6 \%$ with a median value of $21.4 \%$. This was significantly lower than that of normal control subjects $(p<0.001)$. Eleven of the 30 patients had in vitro monocyte maturation within the normal range and median survival in this group was 12 months at the end of the study period. In contrast, 19 patients with monocyte maturation below that in the normal controls had a median survival of only eight months (fig 1). Actuarial survival curves for the two groups are shown in fig 2 and are significantly different $(\mathrm{p}<0 \cdot 05)$. Whereas all patients with in vitro monocyte maturation within the normal range survived for eight months, only 10 of the $19(53 \%)$ of those with low monocyte maturation remained alive after this time.

Twenty-four patients with limited squamous cell carcinoma of the lung came to surgery and five of these proved to be inoperable. Preoperative monocyte maturation in these five ranged from $3 \cdot 1$ to $24.3 \%$ with a median value of $6 \cdot 1 \%$. Median survival in this group was four months. In those who proved to be operable the range was 5.0 to $57.6 \%$ with a median of $31.3 \%$, significantly higher than in those who were inoperable $(p<0 \cdot 01)$.

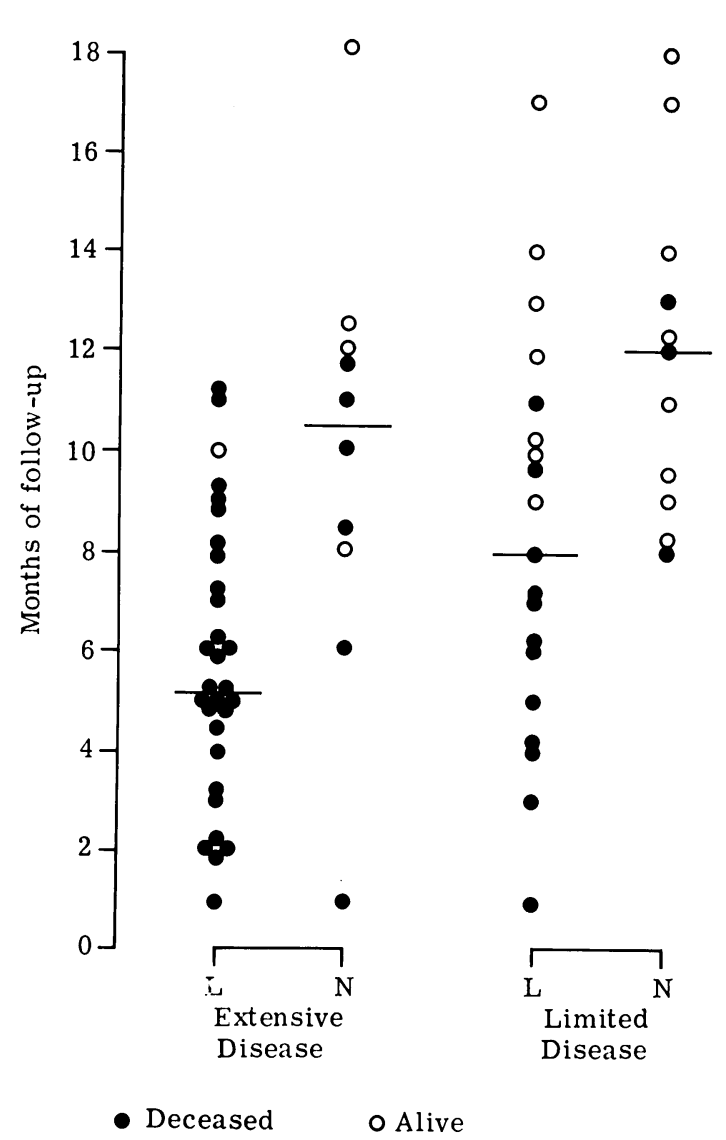

Fig 1 Survival times for patients with limited and extensive squamous cell carcinoma of the lung having either normal $(N)$ or low $(L)$ in vitro monocyte maturation; $\mathrm{O}=$ deceased; $\mathrm{O}=$ still alive; bars represent median values.

Median survival in those who were operable was 11 months.

PATIENTS WITH SQUAMOUS CELL CARCINOMA OF THE LUNG

Monocyte maturation in 40 patients with extensive disease ranged from 2.4 to $52.9 \%$ with a median of $13.2 \%$. This was significantly less than normal controls $(p<0.001)$ and patients with limited disease $(p<0.025)$. Ten of the 40 patients had normal monocyte maturation and median survival in this group was 10.5 months compared with 5.25 months in those 30 patients with maturation below the normal range (fig 1). Eight of the 10 patients with normal in vitro monocyte maturation remained alive at eight months $(80 \%)$ compared 


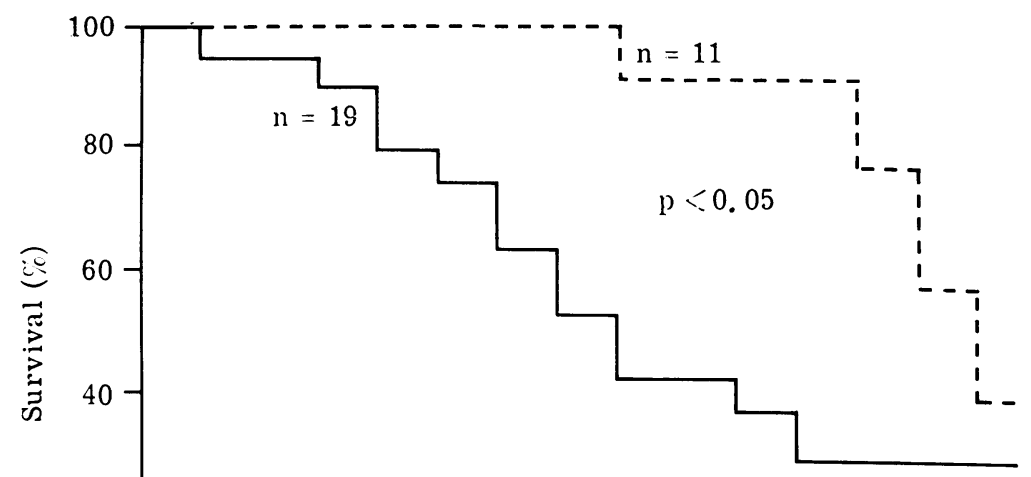

Fig 2 Survival curves for patients with limited squamous cell carcinoma of the lung with in vitro monocyte maturation within or below the normal range $(30.4$ to $62.0 \%)$.
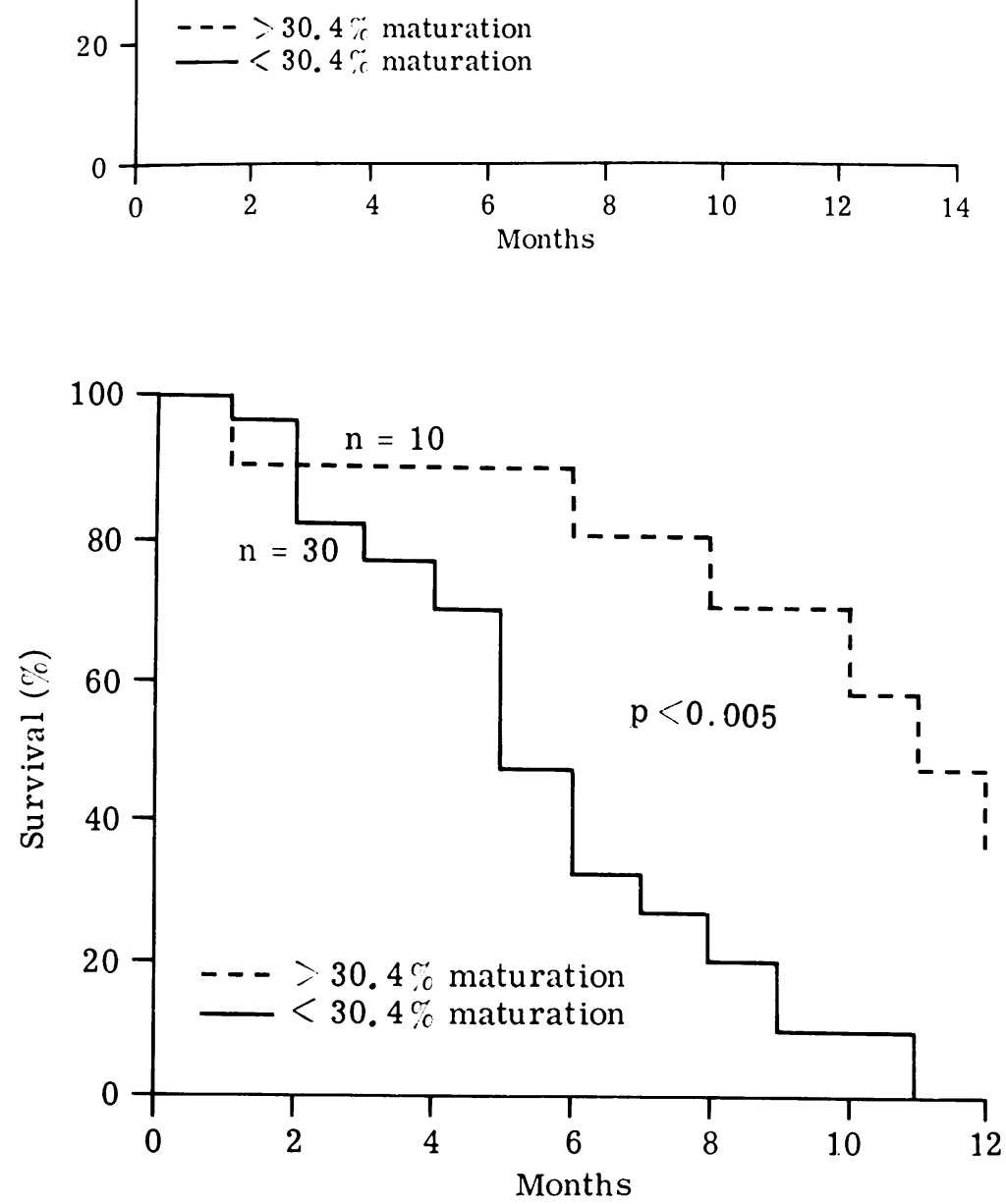

Fig 3 Survival curves for patients with extensive squamous cell carcinoma of the lung with in vitro monocyte maturation within or below the normal range $(30 \cdot 4$ to $62 \cdot 0 \%)$.

with eight of the 30 with low maturation (27\%). Actuarial survival curves for these two groups are shown in fig 3 and show that survival in the two was significantly different when assessed by the log rank procedure $(\mathrm{p}<0.005)$.

\section{Discussion}

In vitro monocyte maturation is depressed in patients with squamous cell carcinoma of the lungo and this cannot be explained by the coexistences 
of chronic obstructive airways disease, infection, smoking habit, or debility. The results described in this study show that there is a relation between in vitro monocyte maturation and survival, even if the patients with limited disease are considered separately from those with extensive disease. The patients with poor monocyte maturation were comparable clinically with those with normal maturation (tables 1 and 2). In particular, general performance status (Karnofsky score), weight loss, and sex distribution were similar in the groups, all clinical features that have been related to the prognosis of patients with lung cancer as well as to extent of disease. ${ }^{910}$ The degree of debility, as judged by the level of serum albumin was not significantly different in the groups with low and normal maturation.

All those patients with normal monocyte maturation at presentation and with clinically limited disease remained alive at eight months, despite the fact that two of them were unfit for surgery because of poor respiratory function. None of the

Table 1 Clinical features of patients with limited squamous cell carcinoma of the lung

\begin{tabular}{|c|c|c|}
\hline \multirow[t]{2}{*}{ Clinical feature } & \multicolumn{2}{|c|}{ In vitro monocyte maturation } \\
\hline & $\begin{array}{l}\text { Normal } \\
(>30.4 \%)\end{array}$ & $\begin{array}{l}\text { Low } \\
(<30.4 \%)\end{array}$ \\
\hline Male & 8 & 15 \\
\hline Female & 3 & 4 \\
\hline Mean age (yr) & $63 \cdot 8$ & $61 \cdot 5$ \\
\hline Mean Karnofsky score & $7 \cdot 8$ & $8 \cdot 2$ \\
\hline Loss of weight $>8 \mathrm{lbs}(\%)$ & 1 (10) & 3 (16) \\
\hline Mean diameter of tumour in $\mathrm{cm}$ (n) & $4 \cdot 2(9)$ & $4 \cdot 5(16)$ \\
\hline Mean lymphocyte count $\left(\times 10^{8} / 1\right)$ & 1900 & 1800 \\
\hline Mean monocyte count $\left(\times 10^{6} / 1\right)$ & 420 & 412 \\
\hline Mean serum albumin $(\mathrm{g} / \mathrm{l})$ & $40 \cdot 6$ & $38 \cdot 8$ \\
\hline Surgery & 9 & 15 \\
\hline Unfit for surgery & 2 & 4 \\
\hline Immunotherapy & $\mathbf{0}$ & 1 \\
\hline Radiotherapy & 0 & 1 \\
\hline
\end{tabular}

Table 2 Clinical features of patients with extensive squamous cell carcinoma of the lung

\begin{tabular}{|c|c|c|}
\hline \multirow[t]{2}{*}{ Clinical feature } & \multicolumn{2}{|c|}{ In vitro monocyte maturation } \\
\hline & $\begin{array}{l}\text { Normal } \\
(>30.4 \%)\end{array}$ & $\begin{array}{l}\text { Low } \\
(<30.4 \%)\end{array}$ \\
\hline $\begin{array}{l}\text { Male } \\
\text { Female } \\
\text { Mean age (yr) } \\
\text { Mean Karnofsky score } \\
\text { Loss of weight }>8 \mathrm{lbs}(\%) \\
\text { Mean diameter of tumour in cm (n) } \\
\text { Mean lymphocyte count }\left(\times 10^{\circ} / 1\right) \\
\text { Mean monocyte count }\left(\times 10^{8} / 1\right) \\
\text { Mean serum albumin }(\mathrm{g} / \mathrm{l}) \\
\text { Evidence of metastases } \\
\text { Treated with radiotherapy } \\
\text { Treated with insertion of gold grains }\end{array}$ & $\begin{array}{l}8 \\
2 \\
63 \cdot 3 \\
7 \cdot 2 \\
4 \cdot(40) \\
5 \cdot 0(5) \\
1500 \\
530 \\
35 \cdot 8 \\
5 \\
4 \\
1\end{array}$ & $\begin{array}{l}25 \\
5 \\
66 \cdot 7 \\
7 \cdot 0 \\
14 \quad(47) \\
5 \cdot 6(22) \\
1200 \\
595 \\
32 \cdot 6 \\
12 \\
8 \\
0\end{array}$ \\
\hline
\end{tabular}

nine patients with normal maturation proved to be inoperable at thoracotomy. In marked contrast was the behaviour of the 19 patients with clinically limited disease but low monocyte maturation. Fifteen of these patients were considered fit for surgery but five proved to be inoperable and overall seven of this group had died by eight months. Five patients in this group had particularly low monocyte maturation $(<10 \%)$ and they fared especially poorly. Four of the five had inoperable disease, two being dead within only 3.5 months. The fifth patient had a large $8 \times 8 \mathrm{~cm}$ diameter tumour resected and received postoperative immunotherapy in the form of intrapleural BCG (Tice strain $10^{7}$ viable organisms $/ \mathrm{ml}$ ). Repeat monocyte maturation at eight weeks after operation was $31.5 \%$ and this patient remains alive and disease-free 13 months later, suggesting that treatment can reverse the depression of monocyte function. Only one patient with monocyte maturation greater than $10 \%$ proved to be inoperable. It may be concluded that normal monocyte maturation at presentation in patients with clinically limited disease is likely to be associated with operability and a good prognosis but that poor maturation, especially below $10 \%$, may indicate inoperability and correspondingly poor survival. A further study is being undertaken to assess whether postoperative monocyte maturation predicts survival any better than preoperative in those who prove to be operable.

The analysis of monocyte maturation in patients with extensive disease provided an even stronger indication of survival with $80 \%$ of patients with normal maturation alive at eight months compared with only $27 \%$ of patients with low values. Values below $10 \%$ were associated with particularly poor survival, 15 of 17 patients dying before eight months with a median survival of only 4.9 months.

The results may be explained in a number of ways. First, poor monocyte maturation may be an artefact of in vitro study and have no relevance to monocyte function in vivo. This is a possibility with all in vitro tests of cellular function but the fact that such a correlation with survival exists suggests that the observation may be relevant. Depression of in vitro monocyte maturation has also been reported in patients with malignant melanoma ${ }^{4}$ and breast carcinoma. ${ }^{11}$ In patients with primary breast carcinoma those who relapse in the first year after surgical removal have the lowest preoperative monocyte maturation, ${ }^{11}$ suggesting this in vitro assay has some relevance. Other in vitro monocyte functions that have been found to be depressed in cancer patients, 
such as monocyte chemotaxis, ${ }^{12}{ }^{13}$ have confirmed similar findings in vivo. ${ }^{14}$

The second possibility is that patients with poor monocyte function are those who develop more malignant disease. If this were the case, and abnormal monocyte function preceded the development of neoplasia, then control groups matched for the presence of coexistent disease, infection, smoking and so on would be expected to contain a proportion of patients with similarly poor monocyte function. This has not been found to be the case in our studies, as yet unpublished.

The third possibility is that monocyte function is altered in patients with cancer as a result of the presence of the tumour. The evidence favours this possibility since patients with more extensive disease have significantly more depressed in vitro monocyte maturation, a finding confirmed in studies of patients with malignant melanoma ${ }^{4}$ and breast carcinoma. ${ }^{11}$ The implantation of tumour into animals causes depression of monocyte chemotaxis and the presence of extracts of tumour depresses a number of monocyte and macrophage functions in vitro as reviewed by James. ${ }^{15}$ If this is the case, in vitro monocyte maturation may be reflecting production by the tumours of inhibitory materials that affect monocyte function, and possibly other anti-tumour effector mechanisms, thus explaining the relation to survival.

Poor delayed hypersensitivity skin responses to specific antigen have been correlated with poor survival in patients with lung cancer by a number of workers, ${ }^{16-18}$ and this has been assumed to reflect depression of specific cell-mediated immune mechanisms involving the lymphocyte. However, it is now appreciated that normal mononuclear phagocytes as well as sensitised lymphocytes are necessary for the development of a positive skin response, ${ }^{19}$ and it is therefore possible that abnormal MPS function underlies negative skin responses. ${ }^{20} 21$ MPS cells have also been shown to be necessary for the in vitro proliferative response of lymphocytes to specific (PPD) and non-specific(for example, PHA) mitogens. Abnormal MPS numbers or function may therefore explain the poor lymphocyte transformation recorded so often in patients with lung cancer. ${ }^{22}$

In vitro monocyte maturation is easy and cheap to perform, is reproducible, and provides an indication of prognosis in patients with both limited and extensive squamous cell carcinoma of the lung. It may help to explain the finding of poor delayed hypersensitivity skin responses in patients with lung cancer and may prove useful in assessing the suitability of patients for surgery.

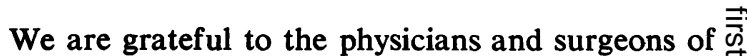
Brompton Hospital for allowing us to study their patients. RGD was supported by a Brompton 흘 Hospital Clinical Research Committee grant. This $\frac{\bar{m}}{\square}$ work was supported by the Medical Research $\stackrel{\mathscr{Q}}{\mathscr{Q}}$ Council. The secretarial assistance of Miss M Ash is acknowledged gratefully.

\section{References}

1 Mantovani A, Jerrells TR, Dean JH, Herberman $\overrightarrow{\vec{x}}$ RB. Cytolytic and cytostatic activity on tumor $\dot{\omega}$ cells of circulating human monocytes. Int J Cancer 1979; 23:18-27.

2 Lauder I, Aherne W, Stewart J, Sainsbury R. $\stackrel{\vec{f}}{\circ}$ Macrophage infiltration of breast tumours: $a_{\circ}$ prospective study. J Clin Path 1977; 30:563-8.

3 Hibbs JB, Lambert LH, Remington JS. Adjuvant induced resistance to tumor development in mice. Proc Soc Exp Biol Med 1972; 139:1053-6.

4 Karnofsky D. Clinical evaluation of chemothera- $\vec{\bullet}$

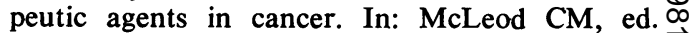
Evaluation of chemotherapeutic agents. New York: Columbia University Press, 1949:191.

5 Currie GA, Hedley DW. Monocytes and macrophages in malignant melanoma. I. Peripheral blood macrophage precursors. Br J Cancer 1977; ڤँ 36:1-6.

6 Yam LT, Li CY, Crosby WH. Cytochemical identification of monocytes and granulocytes. $A m$ 윽 J Clin Path 1970; 55:283-90.

7 Peto R, Pike M, Armitage $P$ et al. Design and analysis of randomized clinical trials requiring prolonged observation of each patient. II. Analysis and examples. Br J Cancer 1977; 35:1-39.

8 Mann HB, Whitney DR. On a test of whether $\tilde{x}$ one of two random variables is stochastically larger than the other. Ann Math Statist 1947; 18: $50-60$.

9 Hyde L, Wolf J, McCracken S, Yesner R. Natural course of inoperable lung cancer. Chest 1973; 64:응 309-12.

10 Lagakos SW. Prognostic factors for survival time $\frac{7}{0}$ in inoperable lung cancer. In: Straus MJ, ed. Lung cancer. Clinical diagnosis and treatment. $\widetilde{\sigma}$ New York: Grune and Stratton, 1977:271-80.

11 Taylor SA, Currie GA. Monocyte maturation and prognosis in primary breast cancer. $\mathrm{Br} \mathrm{Med} \mathrm{J} \mathrm{W}$ 1979; 1:1050-1.

12 Boetcher DA, Leonard EJ. Abnormal monocyteco chemotactic response in cancer patients. $J$ Natl $\bar{\Phi}_{\overparen{C}}$ Cancer Inst 1974; 52:1091-9.

13 Rubin RH, Cosimi AB, Goetzl EJ. Defective 0 human mononuclear leukocyte chemotaxis as an $\overrightarrow{0}$ index of host resistance to malignant melanoma. Clin Immunol Immunopathol 1976; 6:376-88.

14 Dizon QS, Southam CM. Abnormal cellular response to skin abrasion in cancer patients. Cancer 1963; 16:1288-92.

15 James $K$. The influence of tumour cell products 
on macrophage function in vitro and in vivo. In: James K, McBride W, Stuart A, eds. The macro phage and cancer: proceedings of the Eures symposium. University of Edinburgh, 1977:255-46.

16 Krant MJ, Manskopf G, Brandrup CS, Madoff MA. Immunologic alterations in bronchogenic cancer. Sequential study. Cancer 1968; 21:623-31.

17 Israel L, Mugica J, Chaminian P. Prognosis of early bronchogenic carcinoma. Survival curves of 451 resected lung cancer cases in relation to the results of the pre-operative tuberculin skin test. Biomedicine 1973; 19:68-72.

18 Snell NJC. Tuberculin reactivity as a predictor of survival time in inoperable bronchial carcinoma. Thorax 1979; 34:508-11.
19 Pearsall NN, Weiser RS. The macrophage. Philadelphia: Lea and Febiger, 1970:101.

20 Hawes CS, Kemp AS, Jones WR. Random monocyte migration: in vitro correlation with the delayed hypersensitivity skin reaction. Clin Exp Immunol 1979; 37:567-71.

21 Johnson MW, Maibach HI, Salmon SE. Skin reactivity in patients with cancer: impaired delayed hypersensitivity or faulty inflammatory response? N Engl J Med 1971; 284:1255-7.

22 Jerrels TR, Dean JH, Herberman RB. Relationship between $\mathrm{T}$ lymphocyte levels and lymphoproliferative responses to mitogen and alloantigens in lung and breast cancer patients. Int J Cancer 1978; 21:282-90. 